\title{
Synergistic activity and mechanism of action of Stephania suberosa Forman extract and ampicillin combination against ampicillin-resistant Staphylococcus aureus
}

Yothin Teethaisong ${ }^{1}$, Nongluk Autarkool ${ }^{1}$, Kittipot Sirichaiwetchakoon ${ }^{1}$, Pongrit Krubphachaya ${ }^{2}$, Sajeera Kupittayanant ${ }^{3}$ and Griangsak Eumkeb ${ }^{1 *}$

\begin{abstract}
Background: Ampicillin-resistant S. aureus (ARSA) now poses a serious problem for hospitalized patients, and their care providers. Plant-derived antibacterial that can reverse the resistance to well-tried agents which have lost their original effectiveness are the research objectives of far reaching importance. To this aim, the present study investigated antibacterial and synergistic activities of Stephania suberosa extracts (SSE) against ARSA when used singly and in combination with ampicillin.

Results: The majority chemical compounds of SSE were alkaloid (526.27 $\pm 47.27 \mathrm{mg} / 1 \mathrm{~g}$ of dried extract). The Minimum inhibitory concentration (MICs) for ampicillin and SSE against all ARSA strains were $>512 \mu \mathrm{g} / \mathrm{ml}$ and $4 \mathrm{mg} / \mathrm{ml}$, respectively. Checkerboard assay revealed synergistic activity in the combination of ampicillin $(0.15 \mu \mathrm{g} / \mathrm{ml})$ and SSE $(2 \mathrm{mg} / \mathrm{ml})$ at fractional inhibitory concentration index $(\mathrm{FICl})<0.5$. The killing curve assay had confirmed that the viability of ARSA was dramatically reduced from $5 \times 10^{5} \mathrm{cfu} / \mathrm{ml}$ to $10^{3} \mathrm{cfu} / \mathrm{ml}$ within $6 \mathrm{~h}$ after exposure to SSE $(2 \mathrm{mg} / \mathrm{ml})$ plus ampicillin $(0.15 \mathrm{\mu g} / \mathrm{ml})$ combination. Electron microscopic study clearly revealed that these ARSA cells treated with this combination caused marked morphological damage, peptidoglycan and cytoplasmic membrane damage, and average cell areas significant smaller than control. Obviously, Immunofluorescence staining and confocal microscopic images confirmed that the peptidoglycan of these cells were undoubtedly disrupted by this combination. Furthermore, the CM permeability of ARSA was also increased by this combination. Enzyme assay demonstrated that SSE had an inhibitory activity against $\beta$-lactamase in concentrations manner.

Conclusions: So, these findings provide evidence that SSE has the high potential to reverse bacterial resistance to originate traditional drug susceptibility of it and may relate to three modes of actions of SSE: (1) inhibits peptidoglycan synthesis, resulting in morphological damage, (2) inhibits $\beta$-lactamases activity, and (3) increases CM permeability. It is widely recognized that many types of drugs are derived from alkaloids. So, this SSE offers the prominent potential to develop a novel adjunct phytopharmaceutical to ampicillin for the treatment of ARSA. Further active ingredients study, toxicity of it, and the synergistic effect on blood and tissue should be performed and confirmed in an animal test or in humans.
\end{abstract}

Keywords: $\beta$-lactam antibiotics, Ampicillin-resistant S. aureus (ARSA) Stephania suberosa Forman, Synergistic activity, Ampicillin

\footnotetext{
* Correspondence: griang@sut.ac.th

${ }^{1}$ School of Pharmacology, Institute of Science, Suranaree University of

Technology, Nakhon Ratchasima 3000, Thailand

Full list of author information is available at the end of the article
} 


\section{Background}

Since Alexander Fleming discovered the first antibiotic, an increased emergence of multidrug resistance in pathogenic bacteria has been globally documented. In London, 38\% of Staphylococcus aureus strains were resistant to penicillin and increased to approximately $90 \%$ in the UK and USA in the recent year [1]. Similarly, 70$80 \%$ of $S$. aureus strains in most of Asian countries were resistant to methicillin [2]. S. aureus infections are notorious etiological pathogens for several human ailments, including pneumonia, meningitis, toxic shock syndrome, bacteremia, wound sepsis, osteomyelitis, and endocarditis [3-5]. This strain is also the second most common cause of bloodstream infection with case fatality rates of approximately 15-25\% [6]. Methicillin-resistant S. aureus (MRSA) is notably one of the greatest threats to human health, and is the major causes of both hospital and community-acquired MRSA infection that affects both hospitalized patients and their health care providers $[7,8]$. Methicillin, like ampicillin, is the one member of penicillins. So, the resistance pattern of $S$. aureus against both drugs are almost the same [9]. $\beta$-lactam antibiotics are the most common and effective agents for treating staphylococcal infections, but current higher resistance levels were reported in these strains. A raised incidence of $\beta$-lactam resistance in MRSA has rapidly emerged due to mediated by acquisition of mecA encoded an additional penicillin-binding protein 2a (PBP2a) resulting in reducing the ability of $\beta$-lactam in binding to its target site. In summation, the production of blaZ encoded $\beta$-lactamase that can hydrolyze and inactivate $\beta$-lactam antibiotic activity, in particular penicillins. This enzyme is also one of the most important resistant mechanisms to $\beta$-lactam in this strain [10-12]. For these problems, searching and development of novel antibacterial compounds or new strategies are urgently required. Plants are well known and being interested sources for new antibacterial agents because they produce an enormous variety compounds to protect themselves from plant pathogens and environmental pathogens [13]. Thus, plant-derived antibacterials are often a source of novel therapeutics, but they have weaker antibacterial activity compared to that of antibiotic generated by bacteria or fungi. Therefore, it should be considered to use in a different paradigm, including combination with conventional antibiotic that has been resisted by bacteria to achieve synergism in treatment of bacterial infections [14].

Phytochemical and antibiotic combination approach has been recommended and tested by several reports for combating multidrug-resistant bacteria by achieving multiply synergistic drug targets, interacting with drugresistant mechanisms of bacteria, and neutralizing and eliminating adverse effects [15-18]. Previous research found that the hasubanalactam alkaloid (glabradine) isolated from Stephania glabra showed antimicrobial activity against Staphylococcus aureus, S. mutans, Microsporum gypseum, M. canis and Trichophyton rubrum greater than those of novobiocin and erythromycin with IZD values of 19-27 cm [19]. To develop novel plant-derived antibacterials, the Stephania suberosa was selected to investigate its antibacterial property. S. suberosa belongs to Genus Stephania and family Menisperamaceae. Plants in this genus have been traditionally used for treatments of asthma, tuberculosis, dysentery, hyperglycemia, cancer, fever, intestinal discomforts, sleep disturbances and inflammation. Also, previous research found that the chemical compounds in this plant were alkaloids such as, $(+)$-Cepharanthine and its derivative, stephasubimine and etc. [20]. Recently, however, limited study is available on antibacterial activity of S. suberosa. Hence, the purpose of this investigation was to test the antibacterial activity and synergism with ampicillin of this plant against ARSA. Some elementary mechanism of actions, such as cytoplasmic membrane $(\mathrm{CM})$ permeabilization, enzyme assay, and transmission electron microscopy, was also studied.

\section{Methods}

\section{Plant preparation and extraction}

Roots of S. suberosa were purchased from Lamtakhong Research Station, NakhonRatchasima Province, Thailand. The plant specimens were deposited at the Thailand $\mathrm{Na}$ tional Herbarium and authenticated in comparison with the voucher specimen no. BK257189 by Dr. Paul J. Grote, a lecturer and plant biologist at Institute of Science, Suranaree University of Technology, Thailand. The roots of $S$. suberosa were cleaned thoroughly and dried under a hot air oven at the $50^{\circ} \mathrm{C}$ until dry. The dried samples were powdered using a grinder. Then, dried powder was extracted with $95 \%$ ethanol using Soxhlet extractor at $75^{\circ} \mathrm{C}$ for $8 \mathrm{~h}$. The extracts were concentrated using a rotary evaporator and were lyophilized to yield a brown powder and a dark brown sticky oil of ethanolic extract.

Preliminary qualitative phytochemical screening analysis was proceeded for notable bioactive compounds, such as alkaloids, tannin, flavonoids, saponins, glycosides, steroids, terpeniods, coumarins and anthocyanin. The methods were achieved in accordance with previous description and slightly modifications [21-24]. Screening for the presence of the total alkaloid content in the extract was also accordingly carried out with previously reported [25]. In brief, $1 \mathrm{~g}$ of the dried extract was alkalinized with $\mathrm{NH}_{4} \mathrm{OH}$, partitioned with chloroform, and evaporated to dryness on a water bath at $60^{\circ} \mathrm{C}$. The net mass of triplicate remaining solid was accurately weighed and expressed as milligrams per $1 \mathrm{~g}$ of dried 
extract. After weighing, the solids were redissolved by $95 \%$ ethanol and confirmed in the presence of alkaloids.

\section{Bacterial strains, antibiotics, chemicals, and antibodies} Clinical isolates of ampicillin-resistant $S$. aureus (ARSA) DMST 20651, 20652 and 20653 were obtained from the Department of Medical Science, National Institute of Health, Ministry of Public Health, Thailand. The reference strain of $S$. aureus ATCC 29213 was obtained from the American Type Culture Collection (ATCC). Ampicillin, $o$-nitrophenol- $\beta$-D-galactoside (ONPG), nisin, $\mathrm{NH}_{4} \mathrm{OH}$, chloroform and $\beta$-lactamase type IV from $\mathrm{En}$ terobacter cloacae were obtained from Sigma-Aldrich, UK. Mueller-Hinton broth was purchased from Oxoid (Basingstoke, UK). Primary mouse monoclonal antiS. aureus peptidoglycan antibody (ab20002), secondary goat polyclonal anti-mouse IgG conjugated with Alexa Fluor 488 (ab150117), and fluoroshield mounting medium with DAPI (ab104139) were purchased from Abcam, UK.

\section{Bacterial suspension standard curve}

In order to obtain a known viable count of bacterial suspension, the method of Liu and company was followed as previously described with some modifications [26]. Mueller-Hinton agar and Cation-adjusted Mueller-Hinton broth (CAMHB) were practiced as a culture medium [27].

\section{Minimum inhibitory concentration (MIC) determinations}

MIC determinations of ampicillin, nisin, and SSE against ARSA strains were performed following the method of Liu et al. [26]; Eumkeb et al. [28] and Clinical and Laboratory Standards Institute [27]. Briefly, bacterial suspension was adjusted to approximately $1 \times 10^{8} \mathrm{cfu} / \mathrm{ml}$ and serial tenfold dilution was performed to achieve $5 \times$ $10^{6} \mathrm{cfu} / \mathrm{ml}$. The diluted inoculum $(0.1 \mathrm{ml})$ of each stain was added to $0.9 \mathrm{ml}$ of CAMHB plus serial dilutions of the antibacterial agents, to give a final concentration approximately $5 \times 10^{5} \mathrm{cfu} / \mathrm{ml}$. Antibiotics used and SSE was prepared by dissolving in sterile distilled water to obtain stock solutions at $1024 \mu \mathrm{g} / \mathrm{ml}$ for antibiotics or $1024 \mathrm{mg} / \mathrm{ml}$ of the extract. Then, the stock was serially twofold diluted to achieve respective concentration. The lowest concentration that showed no visible growth after incubated at $35^{\circ} \mathrm{C}$ for $18 \mathrm{~h}$ was recorded as the MIC. $S$. aureus ATCC 29213 was used as a reference strain.

\section{Checkerboard determination}

The interaction between SSE and ampicillin against ARSA was assayed using checkerboard determination following Eumkeb et al. [28] and Bonapace et al. [29]. Briefly, the cultured and antibacterial agents were prepared and performed similarly with MIC determination. Otherwise, the SSE and ampicillin were combined and incubated at $35^{\circ} \mathrm{C}$ for $18 \mathrm{~h}$. The MICs were determined as the lowest concentration SSE in combination with ampicillin. The FIC index (FICI) was calculated to determine drug interaction, and interpreted as follows:

$$
\begin{aligned}
\text { FIC index }=\mathrm{FIC}_{A}+\mathrm{FIC}_{B}= & \frac{\text { Conc. of } \mathrm{A} \text { in MICs of A }+\mathrm{B}}{\text { MIC of A alone }} \\
& +\frac{\text { Conc. of B in MICs of A }+\mathrm{B}}{\text { MIC of B alone }}
\end{aligned}
$$

Where, $\mathrm{FICI} \leq 0.5$ denoting synergistic; FICI $>0.5-4.0$ denoting no interaction; FICI $>4.0$ denoting antagonism [30].

\section{Killing curve determination}

Killing curve determination was carried out in order to confirm antibacterial and synergistic activities of SSE when used singly and in combination with ampicillin. The viabilities of drug resistant bacteria after exposure to these agents alone and in combination at nine distinct times $(0,0.5,1,2,3,4,5,6$ and $24 \mathrm{~h})$ were counted. The assay was followed the previously described with some modifications [28,31]. Concisely, inocula $\left(5 \times 10^{5} \mathrm{cfu} / \mathrm{ml}\right)$ were exposed to SSE either singly or in combination with ampicillin. Aliquots $(0.1 \mathrm{ml})$ of each exposed time were removed and diluted in normal saline as needed to enumerate 30-300 colonies. The diluted cultures were platted and spread thoroughly on plates containing MHA. After incubating at $35^{\circ} \mathrm{C}$ for $18 \mathrm{~h}$, the growing colonies were counted. The lowest detectable limit for counting is $10^{3} \mathrm{cfu} / \mathrm{ml}$. The experiment was performed in triplicate; data are shown as mean \pm SEM.

The preliminary mechanism of action was performed in duplicate methods for confirmation except for enzyme assay that clearly determine by one method.

\section{Transmission electron microscopy (TEM)}

Ultrastructure damages of ARSA treated with SSE either alone or in combination with ampicillin were examined using TEM. TEM preparations were performed in accordance with previously reported with slight modifications [32]. After preincubated at $35^{\circ} \mathrm{C}$ for $18 \mathrm{~h}$, ARSA strains were adjusted spectrophotometrically to give a final concentration approximately $5 \times 10^{5} \mathrm{cfu} / \mathrm{ml}$. The cultured were grown in the absence of antibacterial agent (control), in SSE alone, ampicillin alone, and SSE plus ampicillin combination, for $4 \mathrm{~h}$ with shaking 110 oscillations $/ \mathrm{min}$ in a water bath at $37^{\circ} \mathrm{C}$. Then, the cultured were harvested by centrifugation at $6000 \times \mathrm{g}$ for $15 \mathrm{~min}$ at $4^{\circ} \mathrm{C}$ and the pellets were fixed in $2.5 \%$ glutaraldehyde (Electron Microscope Sciences; EMS) in $0.1 \mathrm{M}$ phosphate buffer ( $\mathrm{pH}$ 7.2) for $12 \mathrm{~h}$. The samples were then carefully washed twice with $0.1 \mathrm{M}$ phosphate buffer. Post-fixation was carried out with $1 \%$ osmium tetroxide (EMS) in $0.1 \mathrm{M}$ phosphate buffer $(\mathrm{pH} 7.2)$ for $2 \mathrm{~h}$ 
at room temperature. After washing in the buffer, the samples were gently dehydrated with graded ethanol (20\%, 40\%, 60\%, 80\% and 100\%, respectively) for $15 \mathrm{~min}$. Then, infiltration and embedding were performed using Spurr's resin (EMS). The samples were sectioned using an ultramicrotome with a diamond knife and were then mounted on copper grids. Ultimately, the ultrathin sectioned were counterstained with $2 \%(\mathrm{w} / \mathrm{v})$ uranyl acetate for $3 \mathrm{~min}$ and then $0.25 \%(\mathrm{w} / \mathrm{v})$ lead citrate for $2 \mathrm{~min}$. After staining, the specimens were viewed in a Tecnai G2 electron microscope (FEI, USA), operating at $120 \mathrm{kV}$.

In addition, the cell area of these cells from micrographs were calculated by measuring cell width multiplied by cell length $\left(\mathrm{nm}^{2}\right)$ in order to confirm the effects of SEE either used singly and in combination on cell size.

\section{Immunofluorescence staining and confocal microscopy}

Disruption of peptidoglycan after exposure to SSE either used singly or in adjunction with ampicillin was carried out by the immunofluorescence and visualized under a confocal laser scanning microscope. The $18 \mathrm{~h}$ cultured of ARSA was challenged with distinct agents; ampicillin $(256 \mu \mathrm{g} / \mathrm{ml})$, SSE $(2 \mathrm{mg} / \mathrm{ml})$, ampicillin $(0.11 \mu \mathrm{g} / \mathrm{ml})$ plus SEE $(1.5 \mathrm{mg} / \mathrm{ml})$ for $4 \mathrm{~h}$. The cell grown without antibacterial agent was used as a control. After incubation, the cells were harvested by centrifugation and subsequently fixed with $2.6 \%$ paraformaldehyde and $0.04 \%$ glutaraldehyde mixture for $10 \mathrm{~min}$ at room temperature, and $50 \mathrm{~min}$ on ice. Fixed cells were washed and resuspended in PBS, smeared directly to poly-L-lysine coated slides, and air-dried. Nonspecific antibody binding in the samples was blocked with $5 \%$ BSA for $30 \mathrm{~min}$ at room temperature. The specimens were consecutively incubated with the primary antibody (1:800 dilution with PBS containing $2 \%$ BSA), a mouse anti-S. aureus peptidoglycan antibody, in a moist chamber for $1 \mathrm{~h}$. The cells were washed thoroughly with PBS containing 0.1\% Tween 20. The secondary antibody (Alexa 488-conjugated goat antimouse IgG) was prepared by diluting with PBS plus $2 \%$ BSA solution (1:1000) and incubated with the samples for $1 \mathrm{~h}$ in the dark at room temperature, several washed with PBS $+0.1 \%$ Tween 20 . To reduce photobleaching and to counterstain bacterial DNA, the slides were mounted with a few drops of fluoroshield mounting medium containing 4',6-Diamidino-2-Phenylindole (DAPI) [33]. Images were captured and performed with a confocal laser scanning microscope (Nikon 90i A1R) equipped with 100x NA 1.40 oil objective (Nikon), Intensilight fiber illuminator (Nikon) and NIS Elements 4.11 AR/BR B871 (Nikon). DAPI and Alexa 488 were excited at $360 \mathrm{~nm}$ and $488 \mathrm{~nm}$, respectively. The background cell fluorescence was subtracted. An Adobe Photoshop CS5 was used for the figure preparation.

\section{Cytoplasmic membrane (CM) permeability}

SSE used either singly or in combination with ampicillin induced CM permeability were examined by the ability of these antimicrobial agents to disclose cytoplasmic $\beta$ galactosidase activity in bacteria using ONPG as a substrate. ONPG can be cleaved by $\beta$-galactosidase localized within the cytoplasm. The products of $\beta$-galactosidaseONPG reaction were galactose (colorless) and $o$-nitrophenol (yellow). The assays were prepared in according to the methods of Marri et al. and Eumkeb et al. with slight modification $[34,35]$. Shortly, 18 h ARSA cultured was adjusted to $5 \times 10^{5} \mathrm{cfu} / \mathrm{ml}$ and grown in CAMHB without antibacterial agents (control), $2 \mathrm{mg} / \mathrm{ml} \mathrm{SSE}$, $256 \mu \mathrm{g} / \mathrm{ml}$ ampicillin and $1.5 \mathrm{mg} / \mathrm{ml} \mathrm{SSE}$ plus $0.11 \mu \mathrm{g} / \mathrm{ml}$ ampicillin in 110 oscillations $/ \mathrm{min}$ in shaking water bath at $37^{\circ} \mathrm{C}$. These bacterial cells were then compiled to analyze cytoplasmic membrane alteration at six different interval times $(0,1,2,3,4$ and $5 \mathrm{~h})$. Nisin $(8 \mu \mathrm{g} / \mathrm{ml})$ was applied as a positive command. Each sample $2 \mathrm{ml}$ aliquots at each time were transferred to tubes containing ONPG ( $4 \mathrm{mg} / \mathrm{ml})$ plus Phosphate buffered saline (PBS). Observed yellow was recorded as positive $\beta$-galactosidase activity (increased CM permeability), while appearing colorless was recorded as negative $\beta$-galactosidase activity (no effect on CM permeability).

Apart from this, the second cytoplasmic membrane permeabilization experiment was executed to confirm as previously described by Shen et al. [36] and Zhou et al. [37] with some modifications. This method was performed by measurement the release of UV-absorbing material concentrations using UV-VIS spectrophotometer. In brief, the ARSA cultures were prepared on CAMHB for $18 \mathrm{~h}$ at $35^{\circ} \mathrm{C}$. Inocula of $2.0 \mathrm{ml}$ of culture were added into $98.0 \mathrm{ml} \mathrm{CAMHB}$ and shaking at 100 r.p.m. at $37^{\circ} \mathrm{C}$ for $4 \mathrm{~h}$ to give log phase. Bacterial cultures were adjusted in saline to give $5 \times 10^{6} \mathrm{cfu} / \mathrm{ml}$. Log phase of the adjusted cultures $1.0 \mathrm{ml}$ was added to $9.0 \mathrm{ml}$ of $2.5 \mathrm{mmol} / \mathrm{l}$ sodium HEPES buffer (pH 7.0) supplemented with $100 \mathrm{mmol} / \mathrm{l}$ glucose plus $256 \mu \mathrm{g} / \mathrm{ml}$ ampicillin, $2 \mathrm{mg} / \mathrm{ml} \mathrm{SSE} \mathrm{(1/2} \mathrm{MICs),}$ and $0.11 \mu \mathrm{g} / \mathrm{ml}$ ampicillin plus $1.5 \mathrm{mg} / \mathrm{ml} \mathrm{SSE} \mathrm{(} 3 / 4 \mathrm{FIC})$ in each flask to give a final concentration at $5 \times 10^{5} \mathrm{cfu} / \mathrm{ml}$. The flasks of cell suspensions without antibacterial agent were used as the negative control and with 8 $(\mu \mathrm{g} / \mathrm{ml})$ nisin $(1 / 2 \mathrm{MIC})$ was applied as positive control. The bacterial suspensions were incubated at $37^{\circ} \mathrm{C}$ in the shaker water bath. CM permeability was determined after a contact time of $0,0.5,1.0,2.0,3.0$ and $4.0 \mathrm{~h}$. After treatment, samples $(1.0 \mathrm{ml})$ were taken every contact time and filtered through a sterile nitrate cellulose membrane $(0.22 \mu \mathrm{m})$, and $\mathrm{OD}_{260}$ value of the supernatant was taken as a percentage of the extracellular UV-absorbing materials released by cells. All the measurements were done in triplicates in Varian Cary $1 \mathrm{E}$ UV/VIS spectrophotometer [28]. 


\section{Enzyme assay}

The ability of SSE when used alone to deteriorate $\beta$ lactamase type IV activity of $E$. cloacae was performed following the method as previously described by Richards et al. [32] with little modifications. Concisely, benzylpenicillin, a substrate for $\beta$-lactamase type IV, was adjusted to concentrations sufficient to hydrolyze 50-60\% substrate within $5 \mathrm{~min}$. SSE at 1,2 , and $4 \mathrm{mg} / \mathrm{ml}$ were preincubated with enzyme in $50 \mathrm{mM}$ sodium phosphate buffer $(\mathrm{pH} 7.0)$ at $37^{\circ} \mathrm{C}$ for $5 \mathrm{~min}$ prior to adding a substrate. Time-course assay were performed in $0,5,10,15$ and 20 min using methanol/acetic acid (100:1) as a stopping agent. $10 \mu \mathrm{l}$ of each sample was injected to reverse-phase HPLC to analyze the remaining benzylpenicillin. A mobile phase employed was $10 \mathrm{mM}$ ammonium acetate $(\mathrm{pH} 4.5$ acetic acid): acetronitrile $(75: 25)$ with flow rate $1 \mathrm{ml} / \mathrm{min}$, UV detector at $200 \mathrm{~nm}$, Ascentis $\mathrm{C} 18$ column, and $35^{\circ} \mathrm{C}$ for column temperature [9]. The quantity of remaining benzylpenicillin was calculated by comparing the area under the chromatographic curve.

\section{Statistical analysis of experimental data}

All experiments were carried out in triplicate; data were expressed as mean \pm standard error of the mean (SEM) due to it takes into account sample size. Significant differences of cell area in each treated group from TEM, CM permeability and enzyme assay among each treated group at the same interval times were analyzed by oneway ANOVA. A $p$ valve $<0.01$ of Tukey's HSD post-hoc test was considered as statistically significant difference.

\section{Results}

\section{Phytochemical screening, MIC, and checkerboard} determinations

The preliminary phytochemical characteristics results of SSE indicated that the presence of alkaloids, tannins, glycosides, steroids, and anthocyanin were detected. The total alkaloid containing in the extract was $526.27 \pm$ $47.27 \mathrm{mg} / 1 \mathrm{~g}$ of dried extract. The MIC results of SSE, ampicillin, and nisin against ARSA were $4 \mathrm{mg} / \mathrm{ml},>512 \mu \mathrm{g} /$ $\mathrm{ml}$, and $16 \mu \mathrm{g} / \mathrm{ml}$ respectively, while these agents against susceptible $S$. aureus strain was $4 \mathrm{mg} / \mathrm{ml}, 0.25 \mu \mathrm{g} / \mathrm{ml}$, and $0.5 \mu \mathrm{g} / \mathrm{ml}$ respectively (Table 1 ). According to CLSI, these outcomes suggested that ARSA used in this study revealed high resistant to ampicillin and nisin, but susceptible to reference strain S. aureus ATCC 29213. SSE exhibited little inhibitory effect against these strains. In checkerboard assay, based upon FICI calculation, the combination of SSE and ampicillin exhibited synergistic activity at FICI $<0.5$ (Table 1). Obviously, the concentration of ampicillin that can inhibit ARSA growth had considerably reduced from $>512 \mu \mathrm{g} / \mathrm{ml}$ to $0.15 \mu \mathrm{g} / \mathrm{ml}$ in combination with SSE.

\section{Killing curve determinations}

The viable counts for ARSA after exposure to antimicrobial agents at different times are shown in Figure 1. The control cells revealed no reduction in viable counts and steady growth in log phase viable counts throughout $24 \mathrm{~h}$. Whereas, no significant change was observed in cells treated with the SSE and ampicillin alone. Interestingly, the combination of the SSE plus ampicillin exhibited a steady reduction of $5 \times 10^{5} \mathrm{cfu} / \mathrm{ml}$ to $10^{3} \mathrm{cfu} / \mathrm{ml}$ within $6 \mathrm{~h}$ and did not recover within $24 \mathrm{~h}$. These results had also been confirmed antibacterial and synergistic activity of MIC and checkerboard determinations.

\section{TEM}

The electron microscope images were chosen to present from triplicate samples in each group. Electron microscopic investigation clearly exhibited that the cytoplasmic membrane and cell wall of ARSA grown in the absence of antibacterial agent (control) can be undoubtedly distinguished and no damage to ultrastructure was observed (Figure 2a). ARSA treated with ampicillin $256 \mu \mathrm{g} / \mathrm{ml}$ alone showed slight peptidoglycan damage to a minority of these cells (Figure $2 b$ ). A number of these cells treated with SSE $2 \mathrm{mg} / \mathrm{ml}$ caused somewhat peptidoglycan damage (Figure 2c). Besides, these average cell areas were somewhat smaller than the control and ampicillin groups, but not a significant difference $(p>$ 0.01) (Figure 3). These findings indicate that the SSE treated cells cause rather higher peptidoglycan damage than ampicillin treated cells. Obviously, the synergistic effect was observed with the combination of ampicillin plus SSE that these cells demonstrated a lot of these cells exhibited marked morphological damage, noticeable peptidoglycan damage (Figure 2d). Obviously, these average cell areas were significantly smaller than control and others $(p<0.01)$ (Figure 3$)$.

\section{Immunofluorescence staining and confocal microscopy}

Confocal laser scanning images of peptidoglycan-labeled ARSA unambiguously revealed intact coccus-shaped and no damage was observed in control cell (Figure 4). Cells treated with ampicillin and SSE alone showed a slight damage to peptidoglycan, but SSE alone seemed to have more damage than ampicillin alone. Substantial peptidoglycan disruption was seen in cell received ampicillin plus SSE combination. The bright field image of this treated bacterium demonstrated distortion in cell shape (a white arrow). Data from this experiment had ratified damage of ARSA's peptidoglycan after treatment with SSE in adjacent with ampicillin. These results support a predominant mechanism of action of this combination probably be inhibiting peptidoglycan synthesis. 
Table 1 MICs and FICI of SSE, AMP when used either alone or in combination against ARSA

\begin{tabular}{|c|c|c|c|c|c|}
\hline \multirow[t]{2}{*}{ Strains } & \multirow[b]{2}{*}{ AMP $(\mu \mathrm{g} / \mathrm{ml})$} & \multicolumn{2}{|l|}{ MIC } & \multirow{2}{*}{$\begin{array}{l}\text { FIC } \\
\mathrm{AMP}+\mathrm{SSE}(\mu \mathrm{g} / \mathrm{ml}+\mathrm{mg} / \mathrm{ml})\end{array}$} & \multirow[t]{2}{*}{ FIC index } \\
\hline & & SSE (mg/ml) & $\mathrm{NIS}(\mu \mathrm{g} / \mathrm{ml})$ & & \\
\hline S. aureus DMST 20651 & $>512^{R}$ & $4.0^{\mathrm{ND}}$ & 16 & $0.15+2.0$ & $<0.5$ \\
\hline S. aureus DMST 20652 & $>512^{R}$ & $4.0^{\mathrm{ND}}$ & 16 & $0.15+2.0$ & $<0.5$ \\
\hline S. aureus DMST 20653 & $>512^{R}$ & $4.0^{\mathrm{ND}}$ & 16 & $0.15+2.0$ & $<0.5$ \\
\hline *S. aureus ATCC 29213 & $0.25^{\mathrm{s}}$ & $4.0^{\mathrm{ND}}$ & 0.5 & NT & NT \\
\hline
\end{tabular}

${ }^{\mathrm{S}}=$ Susceptible; ${ }^{\mathrm{R}}=$ resistant; ${ }^{\mathrm{ND}}=$ No data in CLSI; NT = not test; AMP = Ampicillin; SSE = S. suberosa crude extract; $\mathrm{NIS}=\mathrm{Nisin} ; \mathrm{FICl} \leq 0.5$ denoting synergistic; $\mathrm{FICl}>$ 0.5-4.0 denoting no interaction; $\mathrm{FICl}>4.0$ denoting antagonism; ${ }^{*}$ S. aureus ATCC 29213 was used as a reference strain.

\section{CM permeability}

The effect of $256 \mu \mathrm{g} / \mathrm{ml}$ ampicillin, $2 \mathrm{mg} / \mathrm{ml} \mathrm{SSE}$ alone and the combination of $0.11 \mu \mathrm{g} / \mathrm{ml}$ ampicillin plus $1.5 \mathrm{mg} / \mathrm{ml} \mathrm{SSE}$ on CM permeability determined by cytoplasmic $\beta$-galactosidase activity is illustrated in Table 2 . The result showed that there was no activity of $\beta$ - galactosidase with increasing time in cells grown without antibacterial agent (control), with ampicillin and SSE alone. Whereas, cell treated with SSE plus ampicillin combination and nisin exhibited $\beta$-galactosidase activity (observed yellow) after $1 \mathrm{~h}$ exposure time. These results indicated that the combination of SSE plus ampicillin revealed the ability to increase CM permeability of ARSA.

Furthermore, the cytoplasmic membrane permeability was measured by UV-absorbing release materials as presented in Figure 5. After treatment ARSA cells with $8 \mu \mathrm{g} / \mathrm{ml} \mathrm{nisin}$, and $0.11 \mu \mathrm{g} / \mathrm{ml}$ ampicillin plus $1.5 \mathrm{mg} / \mathrm{ml}$ SSE could induce the release of $260 \mathrm{~nm}$ absorbing material, which we interpret to be mostly DNA, RNA,

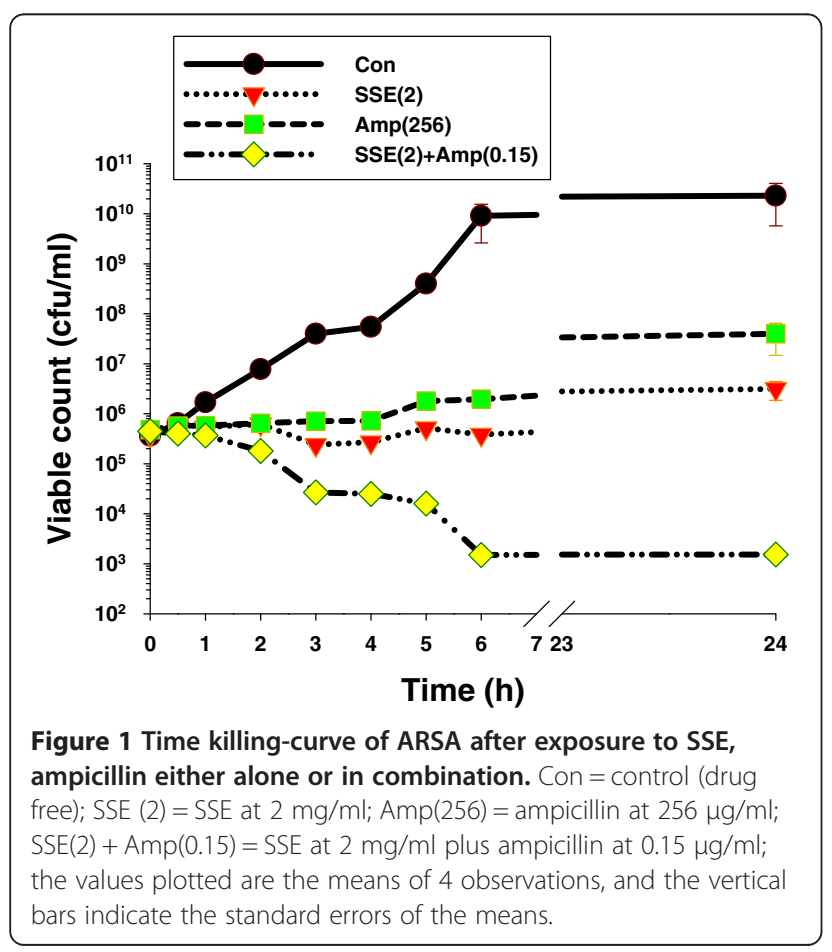

metabolites and ions significantly higher than controls, ampicillin, and SSE alone within $0.5 \mathrm{~h}$ and throughout the $4 \mathrm{~h}(p<0.01)$. These results imply that the synergistic activity of SSE plus ampicillin increased cytoplasmic membrane permeability of this strain [36,37].

\section{Enzyme assay}

The ability of SSE to inhibit activity of $\beta$-lactamase type IV isolated from E. cloacae was assayed by determining the amount of remaining benzylpenicillin using reversephase HPLC. As shown in Figure 6, the result displayed that benzylpenicillin treated with SSE was significantly higher than control starting from 5 minutes $(p<0.01)$. The benzylpenicillin remainder was significantly increased by an increase in SSE as a concentration-dependent manner. These results suggest that one activity of SSE against ARSA may involve in $\beta$-lactamase inhibition [9].

\section{Discussion}

The present investigation is the first report of antibacterial and synergistic activities of S. suberosa extract when used singly and in combination with ampicillin against clinical isolated ARSA. The preliminary mechanisms of action of those agents were also evaluated in this study. Practically-prescribed antibiotic resistance in MRSA due to drug target-site alteration, enzyme modification and changes in membrane permeability, has increasingly emerged. Therefore, the selection of antibiotic to treat multidrug resistant MRSA has been daily decreasing. So, the research approach to find out new anti-MRSA agents are still necessary [4]. The MIC results revealed that these testing $S$. aureus strains were highly resistant to ampicillin alone because of the standard value of the sensitivity of ampicillin against these strains are $\leq$ $0.25 \mu \mathrm{g} / \mathrm{ml}$ [27]. As well as, SSE demonstrated little bacteriostatic effect against these strains while the reference $S$. aureus strain exhibits susceptible to ampicillin. Likewise, these results are in substantial agreement with those of Eumkeb et al. [9] that the MIC of ampicillin against $S$. aureus DMST 20651 was $>1,000 \mu \mathrm{g} / \mathrm{ml}$. Also, the MIC result of nisin against MRSA strains seem consistent with previous finding that $90 \%$ MIC of nisin against MRSA was $16 \mu \mathrm{g} / \mathrm{ml}$ [38]. The checkerboard 


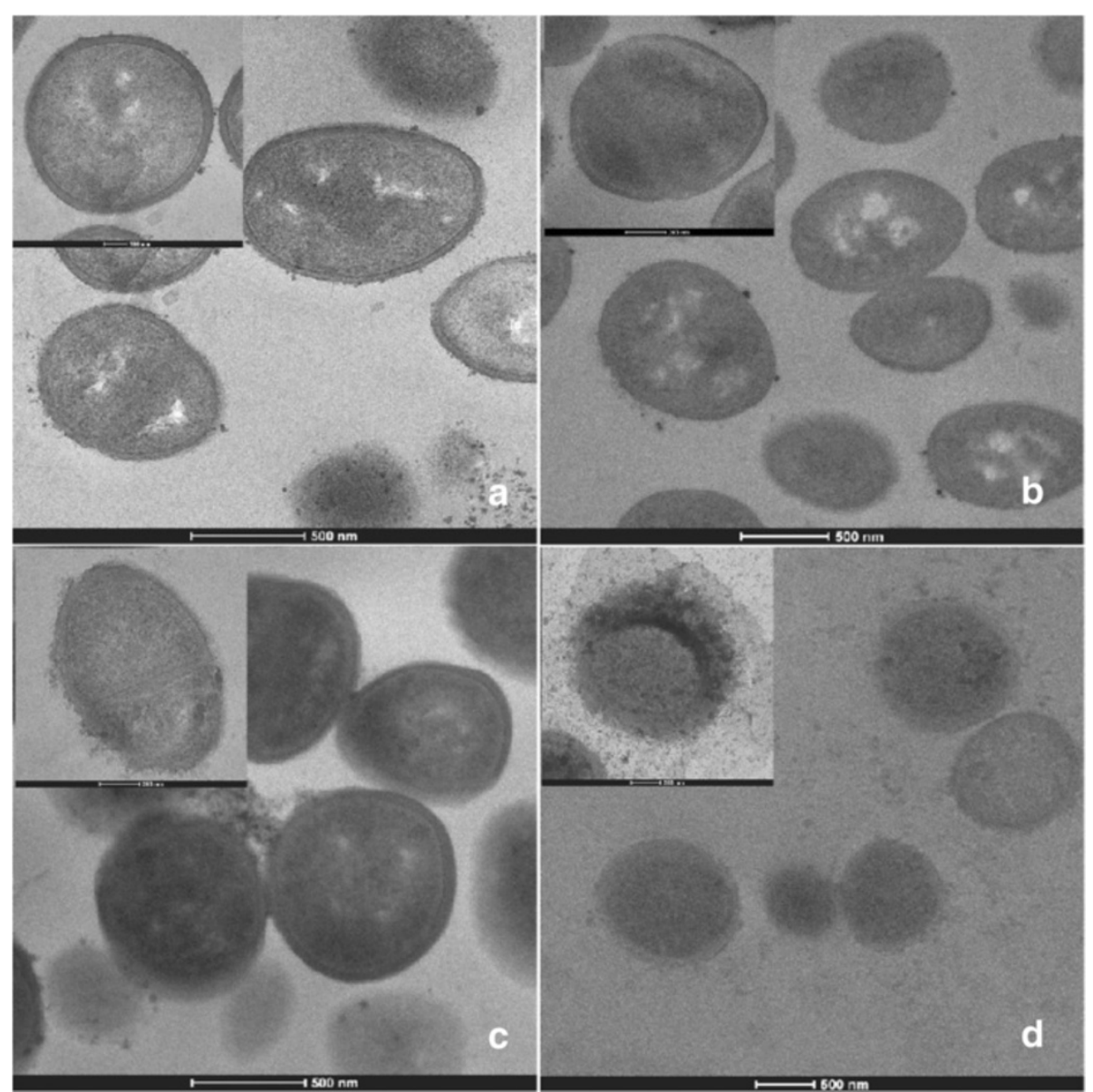

Figure 2 Ultrathin sections of log phase of ARSA DMST 20651 grown in MHB: a = Control (bar = 500 nm, x19500; inset: bar = 100 nm, x43000); b = $256 \mu \mathrm{g} / \mathrm{ml}$ ampicillin (bar = $500 \mathrm{~nm}, x 15000$; inset: bar = $200 \mathrm{~nm}, x 38000) ; \mathrm{c}=2 \mathrm{mg} / \mathrm{ml} \mathrm{SSE}($ bar = 500 nm, x19500; inset: bar = $200 \mathrm{~nm}, x 38000) ; \mathrm{d}=1.5 \mathrm{mg} / \mathrm{ml}$ SSE plus $0.11 \mu \mathrm{g} / \mathrm{ml}$ ampicillin (bar = $500 \mathrm{~nm}$, x8700; inset: bar = $200 \mathrm{~nm}, x 29000$ ).

determination revealed synergistic effects of ampicillin plus SSE against all of tested S. aureus strains with FIC index at $<0.50$ [39]. These results are in substantial correspondence with those of Eumkeb et al. that galangin, quercetin or baicalein plus ampicillin exhibited synergistic activity against penicillins-resistant $S$. aureus strains at FIC indices $<0.03$ [9]. Besides, previous studies reported that a synergistic effect between quercetin and oxacillin against vancomycin-intermediate $S$. aureus displayed the lowest FIC index value of 0.0417 [40]. Apart from this, the antibacterial activity of quercetin plus ampicillin or vancomycin against the sensitive MRSA strain were significantly increased compared to control (no any testing agent) $(p<0.01)$ [41]. As previously documented, drug combination approach by achieving a synergistic effect can eliminate and neutralize the adverse effects [16]. The killing curve determination can confirm MIC and checkerboard determinations that synergistic effect of SSE plus ampicillin caused marked reduction in viable counts of ARSA cells from $6 \mathrm{~h}$ and throughout $24 \mathrm{~h}$. These results appear consistent with previous findings that galangin, quercetin or baicalein plus ceftazidime exhibited synergistic activity against MRSA result in a large decrease from 6 to $24 \mathrm{~h}$ [9], Apart from this, the combinations of baicalin and $\beta$ lactam antibiotics showed that the killing of MRSA and beta-lactam-resistant $S$. aureus cells were dramatic reduction by these combinations [26]. Clearly, the synergistic effect of SSE plus ampicillin against ARSA was observed. For this reason, the elementary mechanism of action such as TEM, CM permeability, and enzyme assay were more investigated.

TEM results of SSE plus ampicillin treated cells demonstrated that ARSA cells exhibited marked morphological damage, clear peptidoglycan and cytoplasmic membrane damage, and average cell areas significant smaller than control. These results seem consistent with previous findings that the combination of ceftazidime plus galangin caused damage to the ultrastructures of the cells, affected the integrity of the cell walls and led 


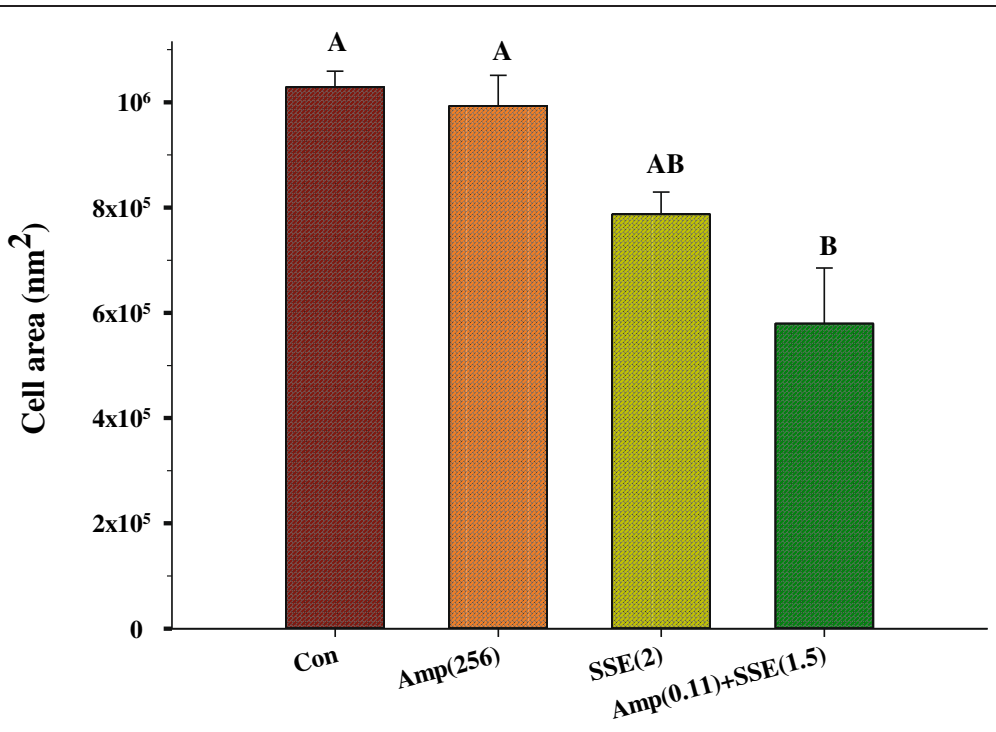

Treated groups

Figure 3 The cell area of ARSA after treatment with SSE, ampicillin either alone or in combination: Con = control (drug free); Amp (256) = ampicillin at $256 \mu \mathrm{g} / \mathrm{ml}$; SSE (2) = SSE at $2 \mathrm{mg} / \mathrm{ml}$; Am (0.11) + SSE (1.5) = ampicillin at $0.11 \mu \mathrm{g} / \mathrm{ml}$ plus SSE at $1.5 \mathrm{mg} / \mathrm{ml}$; The graph shows an area of cell determined by cell width $\mathrm{x}$ cell length $\left(\mathbf{n m}^{2}\right)$. The different superscript alphabets are significantly different from each other. Each treated group was compared using one-way ANOVA and Tukey's HSD Post-hoc test, $p<0.01$ are presented.

to an increase in cell size of ceftazidime-resistant S. aureus [9]. The TEM results have been confirmed by confocal microscopic images that the peptidoglycan of this combination treated cells was undoubtedly destroyed. These effects can be explained by assuming that SSE may insert synergistic action with ampicillin to inhibit peptidoglycan synthesis leads to marked morphological damage and delay cell division.

The CM permeability revealed that SSE in combination with ampicillin increased cytoplasmic membrane

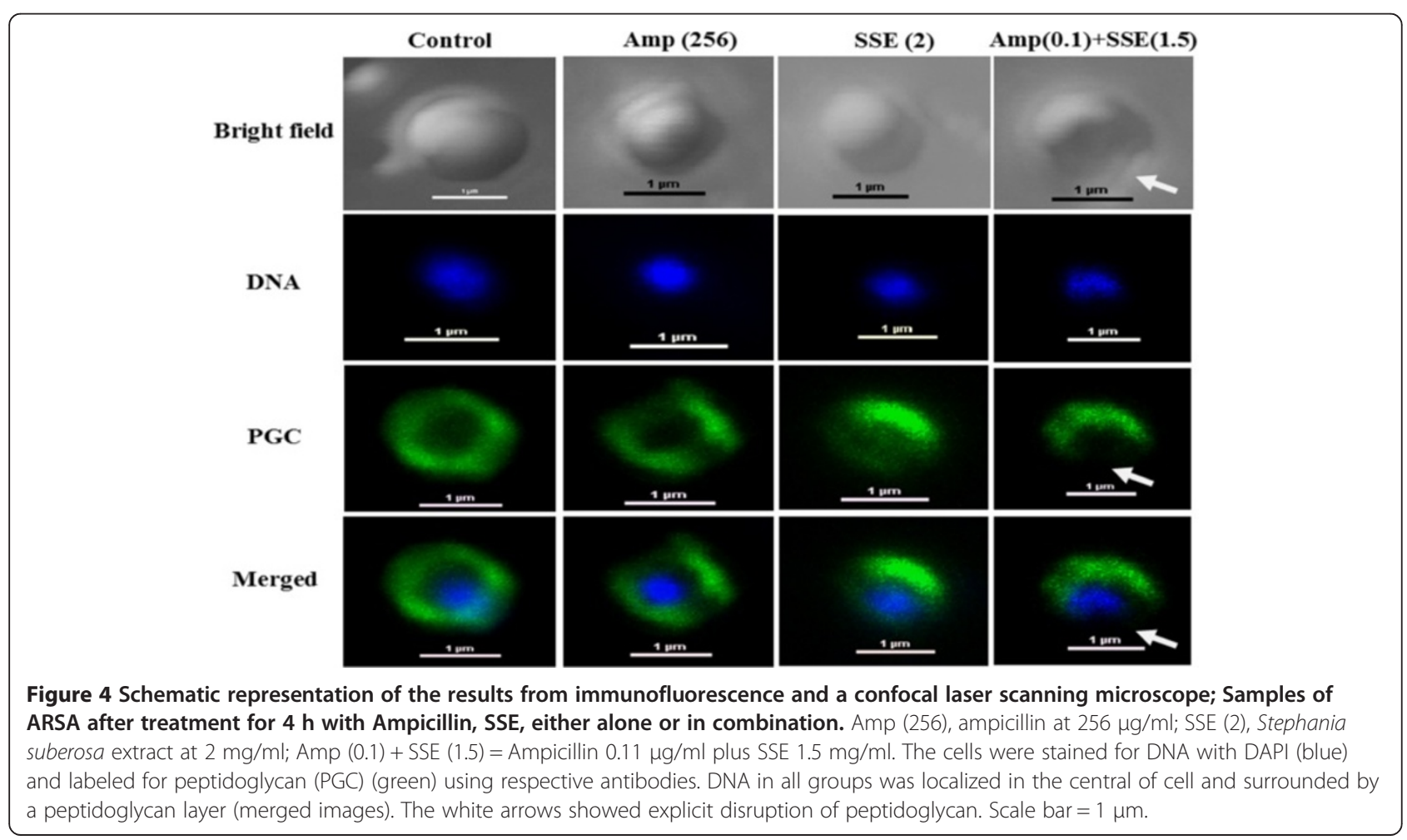


Table $2 \beta$-galactosidase activity results of ARSA after treatment with ampicillin, SSE alone or in combination

\begin{tabular}{cccccc}
\hline Time & Control (no drug) & Amp (256) & SSE (2) & Amp + SSE (0.11 + 1.5) & NIS (8) (positive control) \\
\hline 0 & Neg & Neg & Neg & Neg & Neg \\
1 & Neg & Neg & Neg & Pos & Pos \\
2 & Neg & Neg & Neg & Pos & Pos \\
3 & Neg & Neg & Neg & Pos & Pos \\
4 & Neg & Neg & Neg & Pos & Pos \\
5 & Neg & Neg & Neg & & Pos \\
\hline
\end{tabular}

Neg, no evidence of activity; Pos, have evidence of activity; Amp (256), ampicillin at $256 \mu \mathrm{g} / \mathrm{ml}$; SSE (2), Stephania suberosa extract at $2 \mathrm{mg} / \mathrm{ml}$; Amp + SSE (0.11 + $1.5)=$ Ampicillin $0.11 \mu \mathrm{g} / \mathrm{ml}$ plus SSE $1.5 \mathrm{mg} / \mathrm{ml}$; NIS (8), Nisin at $8 \mu \mathrm{g} / \mathrm{ml}$ was used as a positive control. The experiment was carried out in triplicate observations.

permeability of this strain. The $\beta$-galactosidase activity result was virtually the same as UV-absorbing material concentrations result that CM permeability was significantly increased from $1 \mathrm{~h}$ onward (Table 2 and Figure 5). These results are in substantial agreement with previous findings that luteolin either alone or combined with amoxicillin and apigenin alone and in combination with ceftazidime increased $\mathrm{CM}$ permeability of amoxicillinresistant $E$. coli and ceftazidime-resistant $E$. cloacae respectively $[15,28]$. In general, nisin incorporates into the membrane and makes the membrane permeable for ions. So that, both the membrane potential and $\mathrm{pH}$ gradient are dissipated [42]. Apart from this, nisin inhibits peptidoglycan synthesis and forms highly specific pores through interaction with the membrane-bound cell wall precursor lipid II [43]. The increase in CM permeability may be one of the synergistic activity of this combination

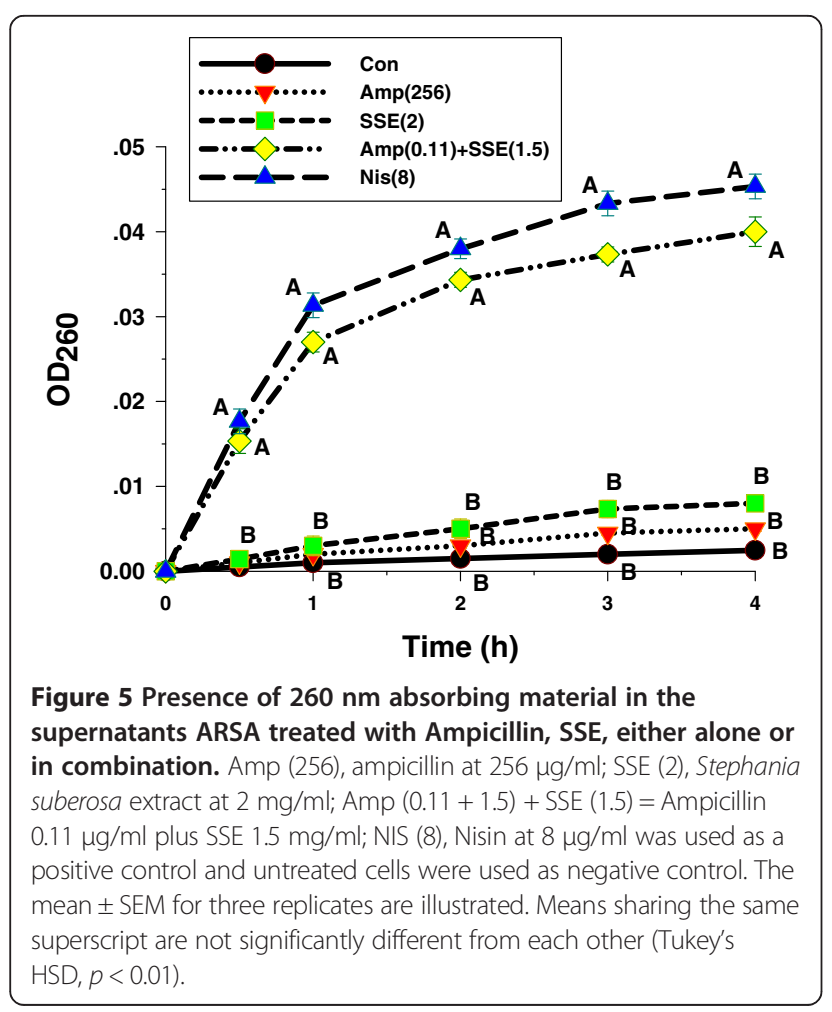

against ARSA strain. The more SSE concentrations results in more benzylpenicillin remainder of enzyme assay results are in substantial agreement with previous findings that galangin inhibits $\beta$-lactamase in a concentrationdependent manner [9]. Noteworthy that the SSE alone could show $\beta$-lactamase inhibitory activity results in very high MIC value. Whereas, its combination with ampicillin showed a synergistic effect by peptidoglycan synthesis inhibition and increase CM permeability. Six new protoberberines and ten known alkaloids were found in Stephama suberosa root extracts [44]. However, the bioactive compounds of S. suberosa extract that showed antibacterial effect in this study have not been well characterized. Although, there is devoid of the report has been documented for toxicity of S. suberosa, but some plant in the genus Stephania, for instance, previous studies found that the $\mathrm{LD}_{50}$ of oral feeding of aqueous extract of Stephania cepharantha wet and dry root tuber in mice were $41.4 \mathrm{~g} /$ $\mathrm{kg}$ and $22.9 \mathrm{~g} / \mathrm{kg}$ respectively [45]. In addition, the acute toxicities of protoberberine alkaloids, berberine, coptisine, palmatine and epiberberine, from Rhizoma coptidis (RC)

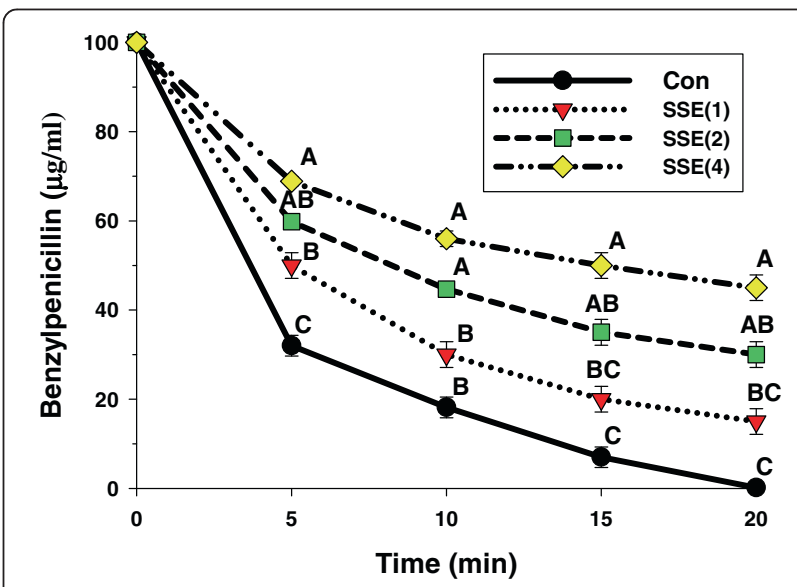

Figure 6 The inhibitory activity of SSE against $\beta$-lactamase type IV from E. cloacae in hydrolyzing benzylpenicillin; Con = control (no testing agent); SSE(1) = SSE at $1 \mathrm{mg} / \mathrm{ml}$. The graph shows the remaining benzylpenicillin at the same time. Means sharing the same superscript are not significantly different from each other (Tukey's HSD, $p<0.01$ ). 
were evaluated, the $\mathrm{LD}_{50}$ value of four alkaloids were $713.57,852.12,1533.68$ and $1360 \mathrm{mg} / \mathrm{kg}$, respectively. The sub-chronic toxicity study in rats treated with the $\mathrm{RC}$ alkaloids at a dose of $156 \mathrm{mg} / \mathrm{kg} /$ day for 90 days revealed that no abnormality in clinical signs, body weights, organ weights, urinalysis, hematological parameters, gross necropsy, histopathology, no mortality and morbidity were observed in any of the animals [46]. Likewise, the acute oral $\mathrm{LD}_{50}$ of lupanine from Lupinus angustifolius in rats was $1464 \mathrm{mg} / \mathrm{kg}$ [47]. Our finding found that the total alkaloid content in SSE was approximately $526.27 \mathrm{mg} / 1 \mathrm{~g}$ of dried extract. The FIC for SSE in combination with ampicillin against ARSA was $2 \mathrm{mg} / \mathrm{ml}$, possibly therefore the total alkaloids of $1.05 \mathrm{mg}$ may roughly presented in $2 \mathrm{mg} / \mathrm{ml}$. In this case, the in vitro determination of starting dose for in vivo tests was used to predict starting doses for subsequent in vivo acute lethality assays. The results lend support to the assumption that if most of these alkaloids are Cepharanthine, the estimated $\mathrm{LD}_{50}$ was $>5,000 \mathrm{mg} / \mathrm{kg}$, which is classified as practically nontoxic $[48,49]$. Hence, SSE when used in combination with ampicillin at this concentration may have a sufficient margin of safety for therapeutic use. Obviously, many alkaloids have been used as modern medicine, for example colchicine (anti-gout), quinine (anti-malaria), morphine and codeine (analgesics), reserpine (anti-hypertension), vinblastine and vincristine (anti-cancer), theophylline (anti-asthma) [50,51]. However, further investigation should be focused on active ingredients of SSE that play an important role on antibacterial effect, as well as toxicity confirmation is still necessary.

\section{Conclusions}

In summary, our study provides evidence that SSE has the extraordinary potential to reverse bacterial resistance to originate traditional drug susceptibility of it. This is the first report of the mechanism of synergistic action of SSE plus ampicillin combination against ampicillinresistant S. aureus. Three modes of actions would be implied that this combination inhibit peptidoglycan synthesis, inhibit $\beta$-lactamases activity, and increase $\mathrm{CM}$ permeability. So, this Stephania suberosa proposes the high potential to develop a useful of novel adjunct phytopharmaceutical to ampicillin for the treatment of ARSA. Future studies should be investigated and confirmed the efficacy and toxicity of this combination in an animal test or in humans, Also, The synergistic effect on blood and tissue would be evaluated and achieved.

\section{Abbreviations}

ARSA: Ampicillin-resistant Staphylococcus aureus DMST 20651; SSE: Stephania suberosa Forman extract; MIC: Minimal inhibitory concentration; FIC: Fraction inhibitory concentration; ATCC: American Type Culture Collection;

CM: Cytoplasmic membrane; cfu: Colony forming unit; CAMHB: Cation-adjusted
Mueller-Hinton broth; OD: Optical density; MHA: Mueller-Hinton agar; HPLC: High performance liquid chromatography; PBS: Phosphate buffer solution; BSA: Bovine serum albumin; DAPI: 4',6-Diamidino-2-Phenylindole; CLSI: Clinical and Laboratory Standards Institute; DMSO: Dimethyl sulfoxide.

\section{Competing interests}

The authors have declared that they have no competing interests.

\section{Authors' contributions}

YT and NA, performed the experiments, analyzed data. KS, PK and SK also analyzed data and gave comments. GE designed the project, supervised the experiments and wrote the report. All authors have read and approved the final manuscript

\section{Acknowledgements}

The authors are indebted and grateful to the Thailand Research Fund for assistance in research fund support through The Royal Golden Jubilee Ph.D. Program (Grant No. PHD/0125/2554) and the One Research One Grant (OROG) scholarship from Suranaree University of Technology, for assistance in research funds support. The following persons are also acknowledged for their invaluable help in carrying out this work; Miss Nualanong Nakkong, Mrs. Phetchara Krubphachaya, Miss Chuenrudee Klangkratok, Mr. Chaiwat Kongmanklang, Miss Kamonluck Teamtisong, and Mr. Suwit Phiasangka, for kind assistance in laboratories.

\section{Author details}

${ }^{1}$ School of Pharmacology, Institute of Science, Suranaree University of Technology, Nakhon Ratchasima 3000, Thailand. ${ }^{2}$ School of Biology, Institute of Science, Suranaree University of Technology, Nakhon Ratchasima 3000, Thailand. ${ }^{3}$ School of Physiology, Institute of Science, Suranaree University of Technology, Nakhon Ratchasima 3000, Thailand.

Received: 21 April 2014 Accepted: 27 August 2014

Published online: 11 September 2014

\section{References}

1. Huttner A, Harbarth S, Carlet J, Cosgrove S, Goossens H, Holmes A, Jarlier V, Voss A, Pittet D: Antimicrobial resistance: a global view from the 2013 World Healthcare-Associated Infections Forum. Antimicrob Resist Infect Control 2013, 2:31

2. Chambers HF: The changing epidemiology of Staphylococcus aureus? Emerg Infect Dis 2001, 7:178-182.

3. Karlsson-Kanth A, Tegmark-Wisell K, Arvidson S, Oscarsson J: Natural human isolates of Staphylococcus aureus selected for high production of proteases and alpha-hemolysin are sigmaB deficient. Int J Med Microbiol 2006, 296:229-236.

4. Mun SH, Joung DK, Kim YS, Kang OH, Kim SB, Seo YS, Kim YC, Lee DS, Shin DW, Kweon KT, Kwon DY: Synergistic antibacterial effect of curcumin against methicillin-resistant Staphylococcus aureus. Phytomedicine 2013, 20:714-718.

5. Engemann JJ, Carmeli Y, Cosgrove SE, Fowler VG, Bronstein MZ, Trivette SL, Briggs JP, Sexton DJ, Kaye KS: Adverse clinical and economic outcomes attributable to methicillin resistance among patients with Staphylococcus aureus surgical site infection. Clin Infect Dis 2003, 36:592-598.

6. Laupland KB, Lyytikainen O, Sogaard M, Kennedy KJ, Knudsen JD, Ostergaard C, Galbraith JC, Valiquette L, Jacobsson G, Collignon P, Schonheyder HC: The changing epidemiology of Staphylococcus aureus bloodstream infection: a multinational population-based surveillance study. Clin Microbiol Infect 2013, 19:465-471.

7. Mehta S, Singh C, Plata KB, Chanda PK, Paul A, Riosa S, Rosato RR, Rosato AE: beta-Lactams increase the antibacterial activity of daptomycin against clinical methicillin-resistant Staphylococcus aureus strains and prevent selection of daptomycin-resistant derivatives. Antimicrob Agents Chemother 2012, 56:6192-6200.

8. Jimenez JN, Ocampo AM, Vanegas JM, Rodriguez EA, Mediavilla JR, Chen L, Muskus CE, Velez LA, Rojas C, Restrepo AV, Garces C, Kreiswirth BN, Correa MM: A comparison of methicillin-resistant and methicillin-susceptible Staphylococcus aureus reveals no clinical and epidemiological but molecular differences. Int J Med Microbiol 2013, 303:76-83.

9. Eumkeb G, Sakdarat S, Siriwong S: Reversing beta-lactam antibiotic resistance of Staphylococcus aureus with galangin from Alpinia 
officinarum Hance and synergism with ceftazidime. Phytomedicine 2010, 18:40-45.

10. Arede $P$, Milheirico $C$, de Lencastre $H$, Oliveira DC: The anti-repressor MecR2 promotes the proteolysis of the mecA repressor and enables optimal expression of beta-lactam resistance in MRSA. PLOS Pathog 2012, 8:e1002816

11. Arede P, Oliveira DC: Proteolysis of mecA repressor is essential for expression of methicillin resistance by Staphylococcus aureus. Antimicrob Agents Chemother 2013, 57:2001-2002.

12. Zhang HZ, Hackbarth CJ, Chansky KM, Chambers HF: A proteolytic transmembrane signaling pathway and resistance to beta-lactams in staphylococci. Science 2001, 291:1962-1965.

13. Chung PY, Navaratnam P, Chung LY: Synergistic antimicrobial activity between pentacyclic triterpenoids and antibiotics against Staphylococcus aureus strains. Ann Clin Microbiol Antimicrob 2011, 10:25.

14. Hemaiswarya S, Kruthiventi AK, Doble M: Synergism between natural products and antibiotics against infectious diseases. Phytomedicine 2008 15:639-652

15. Eumkeb G, Chukrathok S: Synergistic activity and mechanism of action of ceftazidime and apigenin combination against ceftazidime-resistant Enterobacter cloacae. Phytomedicine 2013, 20:262-269.

16. Wagner H: Synergy research: approaching a new generation of phytopharmaceuticals. Fitoterapia 2011, 82:34-37.

17. Worthington RJ, Melander C: Combination approaches to combat multidrug-resistant bacteria. Trends Biotechnol 2013, 31:177-184.

18. Wright GD, Sutherland AD: New strategies for combating multidrugresistant bacteria. Trends Mol Med 2007, 13:260-267.

19. Semwal DK, Rawat U: Antimicrobial hasubanalactam alkaloid from Stephania glabra. Planta Med 2009, 75:378-380.

20. Semwal DK, Badoni R, Semwal R, Kothiyal SK, Singh GJ, Rawat U: The genus Stephania (Menispermaceae): chemical and pharmacological perspectives. J Ethnopharmacol 2010, 132:369-383.

21. Al-Daihan S, Al-Faham M, Al-shawi N, Almayman R, Brnawi A, Zargar S, Bhat $R$ : Antibacterial activity and phytochemical screening of some medicinal plants commonly used in Saudi Arabia against selected pathogenic microorganisms. J King Saud Univ Sci 2013, 25:115-120.

22. Savithramma N, Rao ML, Suhrulatha D: Screening of medicinal plants for secondary metabolites. Middle-East J Sci Res 2011, 8:579-584.

23. Xavier J, Johnson N: A study on phytochemical, pharmacological and anti-insecticidal activity of Leucas aspera (WILLD) Linn. Int J Bio Pharm Allied Sci 2013, 2:894-902.

24. Yadav R, Agarwala M: Phytochemical analysis of some medicinal plants. J Geophys Res 2011, 3:10-14.

25. Pochapski MT, Fosquiera EC, Esmerino LA, Dos Santos EB, Farago PV, Santos FA, Groppo FC: Phytochemical screening, antioxidant, and antimicrobial activities of the crude leaves' extract from Ipomoea batatas (L.) Lam. Pharmacogn Mag 2011, 7:165-170.

26. Liu IX, Durham DG, Richards RM: Baicalin synergy with beta-lactam antibiotics against methicillin-resistant Staphylococcus aureus and other beta-lactam-resistant strains of S. aureus. J Pharm Pharmacol 2000, 52:361-366.

27. Clinical Laboratory Standards Institute: Methods for Dilution Antimicrobia Susceptibility Tests for Bacteria That Grow Aerobically. In Clinical and Laboratory Standards Institute document M7-A7 Volume 29. 9th edition. Edited by Matthew AW, Franklin RC, William AC, Micheal ND, George ME, David WH, Janet FH, Mary JF, Jana MS, Donal EL, Danie JS, Fred CT, John DT, Melvin PW, Barbara LZ. Pennsylvania: Clinical and Laboratory Standards Institute; 2012:16-34

28. Eumkeb G, Siriwong S, Thumanu K: Synergistic activity of luteolin and amoxicillin combination against amoxicillin-resistant Escherichia coli and mode of action. J Photochem Photobiol B 2012, 117:247-253.

29. Bonapace CR, Bosso JA, Friedrich LV, White RL: Comparison of methods of interpretation of checkerboard synergy testing. Diagn Microbiol Infect Dis 2002, 44:363-366.

30. Odds FC: Synergy, antagonism, and what the chequerboard puts between them. J Antimicrob Chemother 2003, 52:1.

31. Richards RM, Xing DK: In vitro evaluation of the antimicrobial activities of selected lozenges. J Pharm Sci 1993, 82:1218-1220.

32. Richards RM, Xing JZ, Gregory DW, Marshall D: Mechanism of sulphadiazine enhancement of trimethoprim activity against sulphadiazine-resistant Enterococcus faecalis. J Antimicrob Chemother 1995, 36:607-618.

33. Tocheva El, Matson EG, Morris DM, Moussavi F, Leadbetter JR, Jensen GJ: Peptidoglycan remodeling and conversion of an inner membrane into an outer membrane during sporulation. Cell 2011, 146:799-812.

34. Eumkeb G, Siriwong S, Phitaktim S, Rojtinnakorn N, Sakdarat S: Synergistic activity and mode of action of flavonoids isolated from smaller galangal and amoxicillin combinations against amoxicillin-resistant Escherichia coli. J Appl Microbiol 2012, 112:55-64.

35. Marri L, Dallai R, Marchini D: The novel antibacterial peptide ceratotoxin A alters permeability of the inner and outer membrane of Escherichia coli K-12. Curr Microbiol 1996, 33:40-43.

36. Shen L, Liu D, Li M, Jin F, Din M, Parnell LD, Lai CQ: Mechanism of action of recombinant acc-royalisin from royal jelly of Asian honeybee against gram-positive bacteria. PLoS One 2012, 7:e47194.

37. Zhou K, Zhou W, Li P, Liu G, Zhang J, Dai Y: Mode of action of pentocin 31-1: An antilisteria bacteriocin produced by Lactobacillus pentosus from Chinese traditional ham. Food Control 2008, 19:817-822.

38. Giacometti A, Cirioni O, Barchiesi F, Scalise G: In-vitro activity and killing effect of polycationic peptides on methicillin-resistant Staphylococcus aureus and interactions with clinically used antibiotics. Diagn Microbiol Infect Dis 2000, 38:115-118.

39. Marques MB, Brookings ES, Moser SA, Sonke PB, Waites KB: Comparative in vitro antimicrobial susceptibilities of nosocomial isolates of Acinetobacter baumannii and synergistic activities of nine antimicrobial combinations. Antimicrob Agents Chemother 1997, 41:881-885.

40. Basri DF, Zin NM, Bakar NS, Rahmat F, Mohtar M: Synergistic Effects of Phytochemicals and Oxacillin on Laboratory Passage-Derived Vancomycin-Intermediate Staphylococcus aureus Strain. J Med Sci 2008, 8:131-136.

41. Hirai I, Okuno M, Katsuma R, Arita N, Tachibana M, Yamamoto Y: Characterisation of anti-Staphylococcus aureus activity of quercetin. Int J Food Sci Tech 2010, 45:1250-1254.

42. Gao F, Abee T, Konings W: Mechanism of action of the peptide antibiotic nisin in liposomes and cytochrome c oxidase-containing proteoliposomes. Appl Environ Microbiol 1991, 57:2164-2170.

43. Wiedemann I, Breukink E, van Kraaij C, Kuipers OP, Bierbaum G, de Kruijff B, Sahl H-G: Specific binding of nisin to the peptidoglycan precursor lipid II combines pore formation and inhibition of cell wall biosynthesis for potent antibiotic activity. J Biol Chem 2001, 276:1772-1779.

44. Patra A, Montgomery CT, Freyer AJ, Guinaudeau H, Shamma M, Tantisewie B, Pharadai K: The protoberberine alkaloids of Stephania suberosa. Phytochemistry 1987, 26:547-549.

45. Chen J, Tong Y, Zhang X, Tian H, Chang Z: Acute toxicity of Stephania cepharantha. hong Yao Cai 1999, 22:468-469.

46. Yi J, Ye X, Wang D, He K, Yang Y, Liu X, Li X: Safety evaluation of main alkaloids from Rhizoma Coptidis. J Ethnopharmacol 2013, 145:303-310.

47. Petterson D, Ellis Z, Harris D, Spadek Z: Acute toxicity of the major alkaloids of cultivated Lupinus angustifolius seed to rats. J Appl Toxicol 1987, 7:51-53.

48. National institute of Environmental Health Sciences: Guidance document on using in vitro data to estimate in vivo starting doses for acute toxicity. North Calolina: NIH publication; 2001.

49. Kennedy GL, Ferenz RL, Burgess BA: Estimation of acute oral toxicity in rates by determination of the approximate lethal dose rather than the LD50. J App/ Toxicol 1986, 6:145-148.

50. Bruneton J: Pharmacognosy, Phytochemistry, Medicinal Plants. 2nd edition. Paris: Lavoisier Publishing; 1999

51. Brunton L, Chabner B: Goodman and Gilman's The Pharmacological Basis of Therapeutics. 12th edition. New York: McGraw-Hill; 2011.

\section{doi:10.1186/s12929-014-0090-2}

Cite this article as: Teethaisong et al: Synergistic activity and mechanism of action of Stephania suberosa Forman extract and ampicillin combination against ampicillin-resistant Staphylococcus aureus. Journal of Biomedical Science 2014 21:90. 